\title{
Influence of pre-treatment on zirconium based conversion coating on AA2024
}

\author{
Matilda Zemanováa , Ján Lokaja, Mária Karl'ováa, Jana Madejováb \\ ${ }^{a}$ Institute of Inorganic Chemistry, Technology and Materials, \\ Faculty of Chemical and Food Technology STU in Bratislava, \\ Radlinského 9, 81237 Bratislava, Slovak Republic \\ ${ }^{b}$ Institute of Inorganic Chemistry, SAS, Dúbravská cesta 5, 84536 Bratislava, Slovak Republic \\ matilda.zemanova@stuba.sk
}

\begin{abstract}
A comparison of the influence of two alloy pre-treatments and temperature treatments on the formation and composition of zirconium based conversion coating on the AA2024 alloy has been performed. The investigation employed mass changes, atomic force microscopy (AFM), XRD dispersive spectroscopy (EDX), infrared spectroscopy (IR) and electrochemical tests by open circuit potential (OCP) measurements. Pre-treatment using only alkaline etching is called alkaline pre-treatment. When alkaline etching is followed by de-oxidization in a phosphoric acid solution the process is called acidic pre-treatment. Conversion coatings were formed in Pragokor BL. IR analysis revealed the formation of a phosphate on the alloy surface. EDX analysis showed $\mathrm{Mg}$ dissolution. The $\mathrm{Zr}$ content increased with the temperature of the conversion coating formation. Both pre-treatment methods provided a phosphate layer on the alloy surface.
\end{abstract}

Keywords: aluminium alloy 2024, zirconium based conversion coating, OCP measurement, IR spectroscopy

\section{Introduction}

Automotive and aircraft industry require a surface treatment of metals applying conversion coatings due to their corrosion resistance and adhesion improvement. Conversion treatments in general require a chemical reaction between the metal and a coating solution. The most extensively used conversion coatings are chromate conversion coatings because of their high effectivity and durability, with $\mathrm{Cr}(\mathrm{VI})$ as a part of the application process. Since $\mathrm{Cr}(\mathrm{VI})$ has been reported to be highly toxic and carcinogenic, numerous alternative non-chromate conversion coatings based on elements with chemistry similar to that of chromium have been studied. The alternatives can be divided into three groups: 1) species containing reducible transition metals (compounds of Mo, Mn, V, Tc), the high valent oxoanions of these elements exist in aqueous solution as well as $\mathrm{Cr}$; 2) species containing difficultto-reduce transition metal oxides ( $\mathrm{Zr}, \mathrm{Ti}, \mathrm{Y}, \mathrm{Hf}, \mathrm{Ta})$; and 3) species containing rare-earth metals (Kendig et al., 2003). Elements as $\mathrm{Ti}, \mathrm{Zr}, \mathrm{Ta}, \mathrm{Hf}, \mathrm{Nb}$ form stable oxides in the highest oxidation rate. Among these alternatives, conversion coatings on zirconium basis $(\mathrm{Zr})$ play the key role. Non-toxicity and anticorrosion properties of the element and its ability to form strong bonds with electronegative elements such as chlorine, fluorine and oxygen are attracting attention. Aluminum alloys AA2024, AA5052, AA6061 are used e.g. in military because of their high strength and resistance against damage. AA2024 as one of the most applied alloys is prone to local corrosion due to alloying elements. In the casting process and the following homogenization, the following intermetallics are formed: $\mathrm{CuMgAl}_{2}(\mathrm{~S})$, $\mathrm{Al}_{2} \mathrm{Cu}$ (theta) and $\mathrm{Al}-\mathrm{Cu}-\mathrm{Fe}-\mathrm{Mn}-\mathrm{Si}$. These intermetallics as particles provide preferred cathodic sites on the alloy surface (Boag et al., 2009; Chen et al., 1996; Qi (1) et al., 2016). Conversion coatings on the $\mathrm{Zr}$ basis consist of two layers: outer layer, identified by XPS, contains $\mathrm{Zr}$ as well as oxide, hydroxide and fluoride (Guo et al., 2012; Qi (2) et al., 2016); inner layer is enriched with aluminium. Intermetallic particles influence the coating development with coating growth preferentially above the S-phase. The presence of intermetallic particles leads to the crack formation; on the other hand, areas rich on $\mathrm{Cu}$ are prone to local corrosion (Guo et al., 2012; Chen et al., 1996). Pre-treatment fundamentally influences the coating homogeneity and thus the corrosion resistance. In the present study, two different pre-treatment methods of chromium free conversion coating formation were studied: alkaline and acidic pre-treatment. Alkaline pre-treatment includes oxide layer removal by mechanical polishing, acetone cleaning and degreasing/etching on $\mathrm{NaOH}$ basis. Acidic pre-treatment, in addition to these operations, involves also deoxidization by 4 vol. \% phosphoric acid ( $85 \%$ ). Furthermore, the effect of the conversion reaction temperature on the coating quality was analyzed in situ applying 
electrochemical analysis using OCP measurements. The formed coating was characterized by different methods (EDX, IR, AFM).

\section{Experimental}

\section{Materials and treatments}

AA2024 samples were cut to dimensions of $20 \times 20 \mathrm{~mm}$ and treated by procedures used in aircraft industry: degreasing with acetone, alkaline cleaning and surface deoxidation. The study on pre-treatment influence means a comparison of two processes with/without the application of the deoxidation solution. Conversion coatings on the aluminum alloy surface were prepared using commercial solution Pragokor BP. The effect of temperature $\left(20,40\right.$ and $60^{\circ} \mathrm{C}$ ) of the conversion reaction on the coating quality was investigated. Electrochemical analysis during the coating formation was carried out by OCP measurements in a three electrode system at the scan rate of $1 \mathrm{mV} \mathrm{s}^{-1}$. The tested sample was employed as the working electrode, saturated calomel electrode (SCE) was the reference electrode and graphite served as the counter electrode. After the experiment, the specimens were rinsed, dried and put in a desiccator to set their weight. Then, the samples were weighed and the coatings were characterized using the EDX (Jeol JXA 840), IR (Nicolet 5700) and AFM (Veeco CP-II) methods. EDX determined the $\mathrm{Mg}$ and $\mathrm{Cu}$ content of 6.6 at. \% and 1.5 at. \%, respectively, balanced by $\mathrm{Al}$ for the AA 2024 specimens. For IR spectroscopy, the attenuated total reflection (ATR) technique was used with a diamond crystal and the resolution of $4 \mathrm{~cm}^{-1}$. AFM records were obtained using the tapping mode with the tip radius of $10 \mathrm{~nm}$.

\section{Pre-treatments operations}

Alkaline pre-treatment consists of material degreasing with acetone, drying by hot-air dryer and etching (oxide layer removal) with diamond pastes M15 and M5/3 (3 min each side, Pramet, Czech Republic), and ultrasound (Sonorex, Germany) cleaning in distilled water $(5 \mathrm{~min}$ at laboratory temperature). Treating with $\mathrm{Al}_{2} \mathrm{O}_{3}$ powder with the grain size of $0.4 \mu \mathrm{m}$ (Presi, France, 2 min each side) with rinsing in distilled water and ultrasound cleaning in distilled water ( $5 \mathrm{~min}$ at laboratory temperature). The samples were then dried by a hotair dryer (3 min each) and put in a desiccator for $10 \mathrm{~min}$. Then, the samples were weighted with the precision of $0.1 \mathrm{mg}$ (Mettler, Switzerland). Alkaline pre-treatment continued with mechanical cleaning by commercial alkaline powder ( $3 \mathrm{~min}$ each side) and intensive ultrapure water rinsing. Afterwards, the samples were collected in a special holder with the surface area exposed to the commercial conversion solution at different temperatures. Acidic pretreatment added to the above mentioned procedure also the immersion of samples into a solution of $4 \%$ phosphoric acid. All chemicals used were p.a., the solutions were prepared using ultrapure water and presented results are the average of at least three measurements.

\section{Results and Discussion}

Formation of conversion coating on aluminum alloy AA2024 was studied by OCP in dependence on the immersion time. Fig. 1 depicts the OCP evolution applying alkaline pre-treatment; different temperatures $\left(20{ }^{\circ} \mathrm{C}, 40{ }^{\circ} \mathrm{C}\right.$ a $\left.60{ }^{\circ} \mathrm{C}\right)$ at which the conversion reaction was carried out are shown. The OCP evolution is comparable for all studied temperatures. After the initial drop, steep increase and stabilization of OCP values were observed. The initial drop in the potential can be attributed to the dissolution of the oxide surface layer by free fluorides as ingredients of the conversion agent. The following increase of OCP is ascribed to the coating formation on the alloy surface. At the temperature of $20^{\circ} \mathrm{C}$, OCP decreases until $90 \mathrm{~s}$ from the conversion reaction beginning to the minimum OCP value of $-0.93 \mathrm{~V}$ vs. SCE. After the potential increase until $240 \mathrm{~s}$, the potential stabilizes at the value of $-0.87 \mathrm{~V}$ vs. SCE. At the temperature of $40{ }^{\circ} \mathrm{C}$, the dissolution time is $50 \mathrm{~s}$ and the potential dropped to the value of $-0.77 \mathrm{~V}$. Stabilization of the OCP value started after $210 \mathrm{~s}$ at the OCP value of $-0.67 \mathrm{~V}$ vs. SCE. At $60^{\circ} \mathrm{C}$, dissolution of the surface took $40 \mathrm{~s}$ and the OCP value was $-0.98 \mathrm{~V}$. Stabilization of OCP followed after $290 \mathrm{~s}$ at the OCP value of $-0.73 \mathrm{~V}$ vs. SCE. The shape of the curve showing abrupt drop and increase of the OCP values is more distinctive at higher temperatures.

As follows from Fig. 2, surface dissolution and a slight hint of coating formation can be noticed at the conversion reaction temperature of $20{ }^{\circ} \mathrm{C}$ and $40{ }^{\circ} \mathrm{C}$. However, at the temperature of $60^{\circ} \mathrm{C}$, just a drop of the OCP values was observed, which was ascribed to the progress of the surface dissolution. At the temperature of $20^{\circ} \mathrm{C}$, OCP decreases to the minimum value of $-0.63 \mathrm{~V}$ vs. SCE until $220 \mathrm{~s}$ from the start of the conversion reaction. At $40{ }^{\circ} \mathrm{C}$, surface dissolution took place until $120 \mathrm{~s}$ from the reaction beginning with the minimum OCP value of $-0.99 \mathrm{~V}$ vs. SCE.

Concerning weight changes after the conversion reaction, increase of the specimen weight was recorded after alkaline pre-treatment. At $20^{\circ} \mathrm{C}$, the weight of the samples increased to $0.05 \mathrm{mg} \mathrm{cm}^{-2}$ and at $60{ }^{\circ} \mathrm{C}$ to $0.17 \mathrm{mg} \mathrm{cm}^{-2}$. Acidic pre-treatment is characterized 


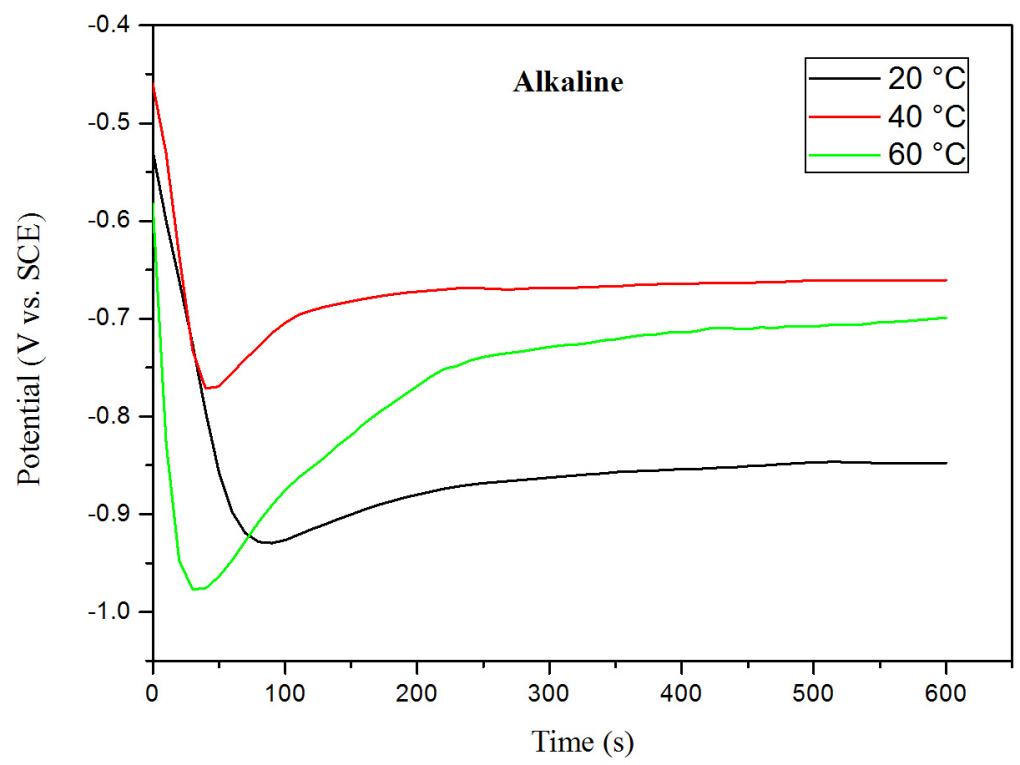

Fig. 1. OCP evolution during the conversion coating deposition applying alkaline pre-treatment.

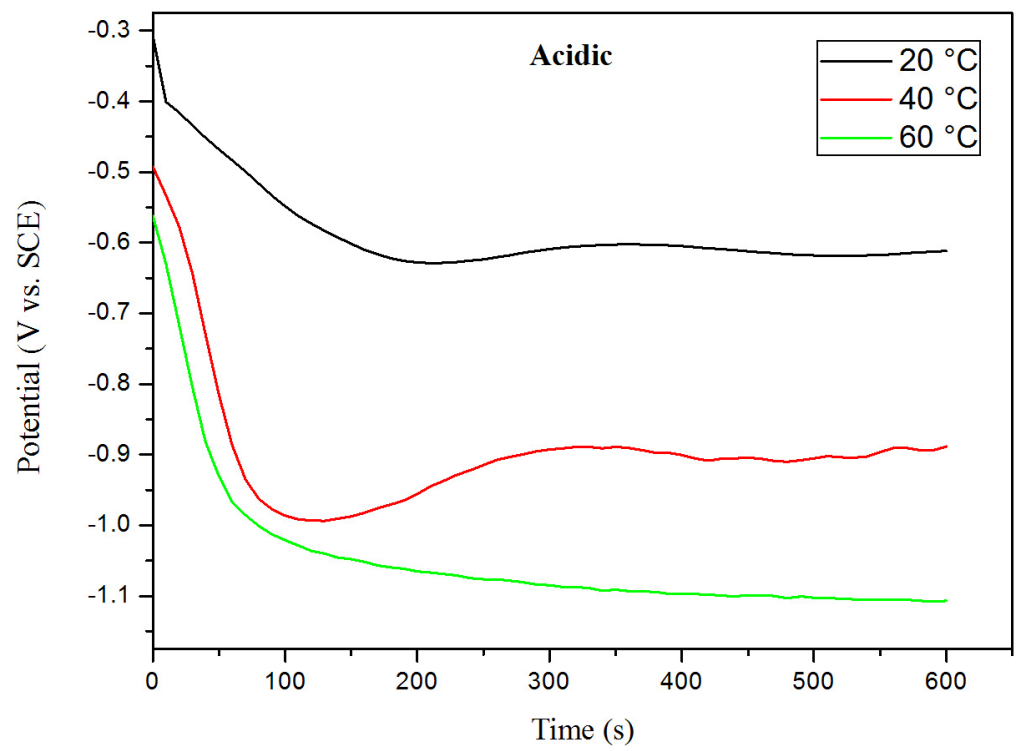

Fig. 2. OCP evolution during the conversion coating deposition applying acidic pre-treatment.

by the decrease of the specimen weight attributed to the prevailing deoxidization reaction over coating formation. The loss of the sample weight increased with the conversion reaction temperature.

Zirconium content on the alloy surface after the conversion reaction was confirmed by EDX analysis (Tab. 1 and Tab. 2); it was observed to increase with the conversion reaction temperature increase. On the other hand, a decrease of the $\mathrm{Mg}$ content was recorded on the specimen surface. On basis of the results it can be concluded that preferential dissolution of the electrochemically active element occurred due to free fluorides present in the conversion solution.
Tab. 1. Element content of conversion coating formed at different reaction temperatures determined by EDX after alkaline pretreatment.

\begin{tabular}{lccccc}
\hline Temperature & $\mathrm{Al}$ & $\mathrm{Mg}$ & $\mathrm{Mn}$ & $\mathrm{Cu}$ & $\mathrm{Zr}$ \\
\hline $20^{\circ} \mathrm{C}$ & 93.30 & 4.59 & 0.26 & 1.68 & 0.17 \\
$40^{\circ} \mathrm{C}$ & 94.37 & 3.02 & 0.35 & 1.93 & 0.34 \\
$60^{\circ} \mathrm{C}$ & 93.50 & 3.82 & 0.32 & 1.45 & 0.91 \\
\hline
\end{tabular}

The same conclusions have been drawn for the acidic pre-treatment. Higher temperatures led to the increase of the zirconium content and decrease of the $\mathrm{Mg}$ content of the conversion coating. 
Tab. 2. Element content of conversion coating formed at different reaction temperatures determined by EDX after acidic pre-treatment.

\begin{tabular}{lccccc}
\hline Temperature & $\mathrm{Al}$ & $\mathrm{Mg}$ & $\mathrm{Mn}$ & $\mathrm{Cu}$ & $\mathrm{Zr}$ \\
\hline $20^{\circ} \mathrm{C}$ & 94.95 & 2.67 & 0.56 & 1.51 & 0.31 \\
$40^{\circ} \mathrm{C}$ & 95.18 & 2.43 & 0.25 & 1.60 & 0.54 \\
$60^{\circ} \mathrm{C}$ & 95.24 & 2.56 & 0.31 & 1.16 & 0.73 \\
\hline
\end{tabular}

IR spectra of the samples prepared by alkaline pre-treatment are shown in Fig. 3a. The broad and intense band centered at $3460 \mathrm{~cm}^{-1}$ was assigned to the $\mathrm{O}-\mathrm{H}$ stretching vibrations of the physically adsorbed water molecules. The peak observed at $1640 \mathrm{~cm}^{-1}$ is due to the bending vibrations of water molecules. Generally, the bands below $800 \mathrm{~cm}^{-1}$ are attributed to the metal-oxygen vibrational modes (Aghazadeh et al., 2012; Nyquist and Kagel, 1971). The broad band at $700 \mathrm{~cm}^{-1}-850 \mathrm{~cm}^{-1}$ is related to the double oxide $\mathrm{Mg}_{2} \mathrm{Al}_{2} \mathrm{O}_{4}$ on the pre-treated AA2024 (Farmer). At different conversion reaction temperatures, only the band at $700 \mathrm{~cm}^{-1}$ remains the same, it reflects the reduction of the double oxide. The band at $1100 \mathrm{~cm}^{-1}$ was observed after the AA2024 reaction with the conversion agent and

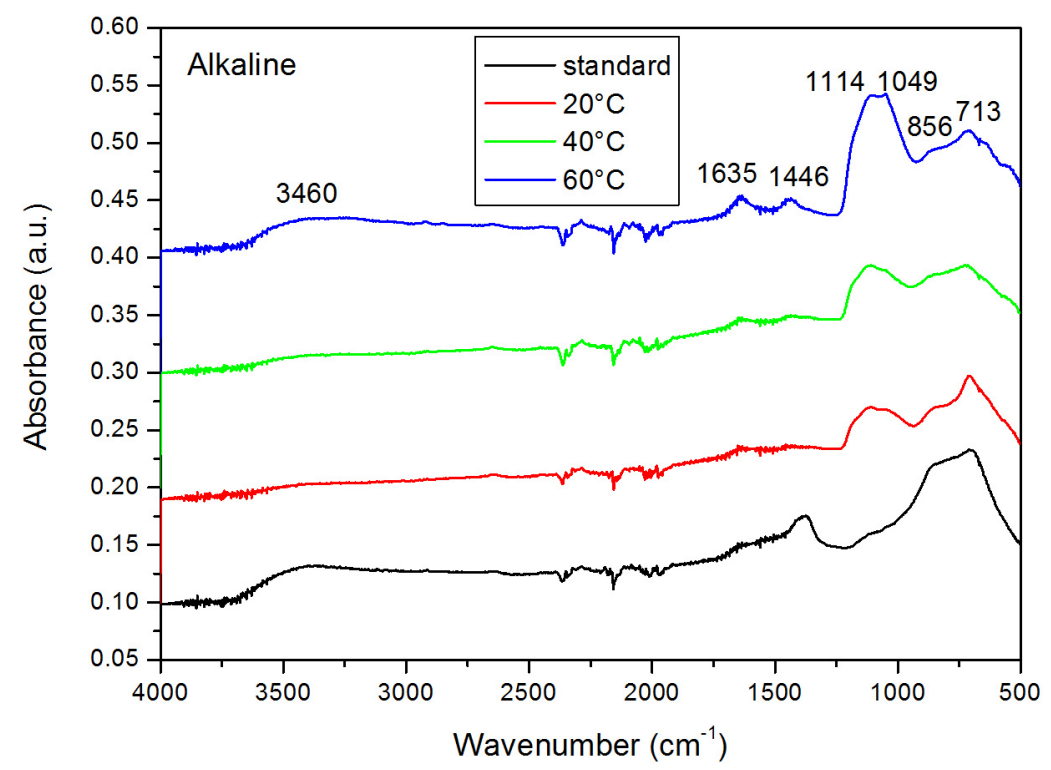

a)

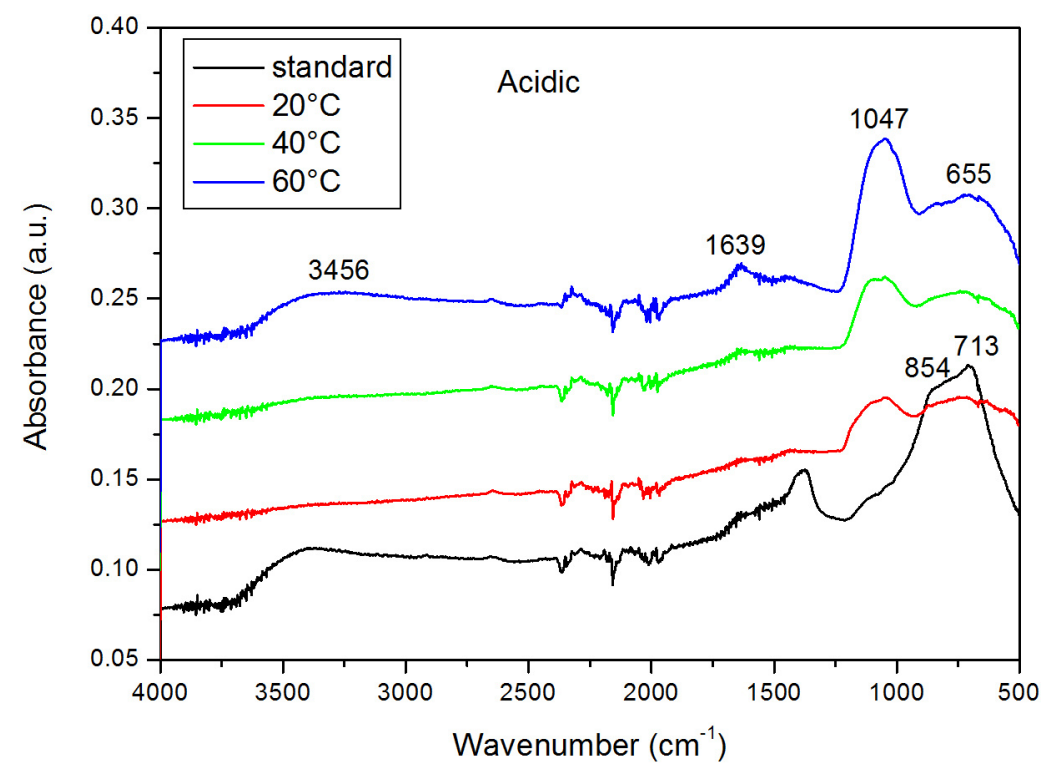

b)

Fig. 3. IR spectra of AA2024 surfaces after the conversion reaction and a) alkaline and b) acidic pre-treatments. 
its intensity depends on the conversion reaction temperature. The band was assigned to the vibrations of the phosphate anions; however, more exact identification of either zirconium or magnesium phosphate is still open (Nyquist and Kagel, 1971). The band characterizing the conversion coating formation is more distinctive at higher temperatures. The same conclusions have been drawn for acidic pre-treatment as it is seen in Fig. 3b.

AFM topography samples treated in a conversion bath at $60{ }^{\circ} \mathrm{C}$ and $10 \mathrm{~min}$ after the alkaline treatment are shown in Fig. 4 . The sample surface consists of nodules and clusters of these nodules at all studied temperatures as it can be seen in Fig 4a. Fig. 4b shows the homogeneity of the coating influenced by the conversion reaction temperature. Morphology of the surface after the conversion reaction at $60{ }^{\circ} \mathrm{C}$ is more fine-grained and homogenous in comparison to surfaces treated at temperatures of $20^{\circ} \mathrm{C}$ and $40{ }^{\circ} \mathrm{C}$. AFM topography after the acidic pre-treatment was not realized due to protrusions on the studied surface.

Based on the obtained results, the following mechanism of the conversion layer on AA20204 surface can be assumed: 1) dissolution of the alloy surface layer due to free fluoride ions and preferential dissolution of magnesium as the electrochemically more active element, 2) reaction with $\mathrm{H}_{3} \mathrm{PO}_{4}$ resulting in phosphate formation. The compound form of $\mathrm{Zr}$ present in the coating is still to be determined.

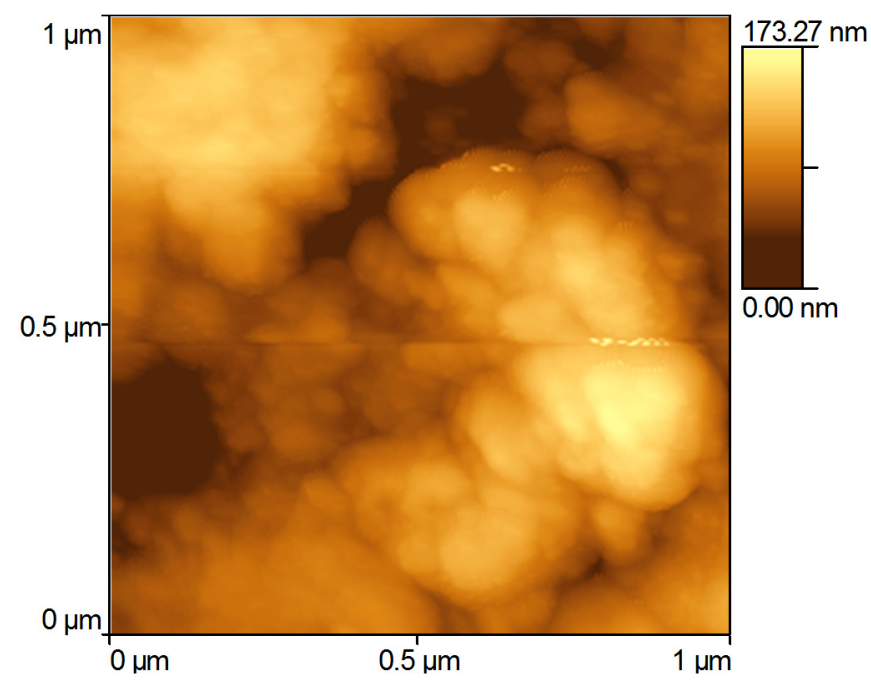

a)

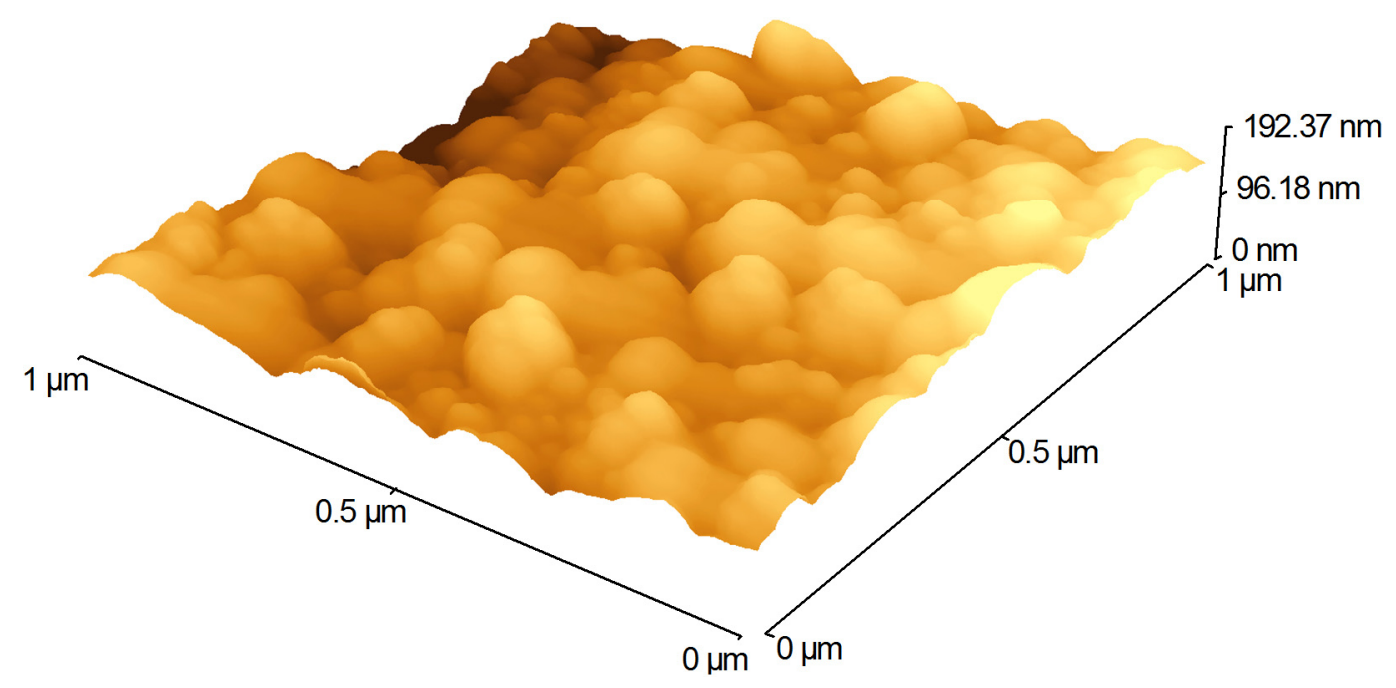

b)

Fig. 4. AFM topography of AA2024 surfaces after the conversion reaction and alkaline pre-treatment at a) $20^{\circ} \mathrm{C}$ and b) $60^{\circ} \mathrm{C}$. 


\section{Conclusion}

The purpose of the work was to prepare and characterize the coating formed by a conversion solution containing zirconium on aluminum alloy 2024. Zirconium coating represents one of the options of more environmentally friendly surface treatment compared to the chromium-based coatings. The effect of pre-treatment and the conversion reaction temperature was determined considering the quality of the formed coating. The choice of the alkaline pre-treatment of aluminum alloy 2024 at $60{ }^{\circ} \mathrm{C}$ seems to be appropriate for the surface quality evaluation of the material. After coating characterization by several methods (X-ray microanalysis, infrared spectroscopy, atomic force microscopy), the presence of zirconium and phosphate on the surface of the treated material and the temperature effect on the surface homogeneity and grain size of the coating have been proved.

\section{Acknowledgement}

This publication is the result of the project implementation: Centre for materials, layers and systems for applications and chemical processes under extreme conditions - Stage
II, ITMS No.: 26240120021 supported by the Research \& Development Operational Programme funded by the ERDF.

\section{References}

Aghazadeh M, Malek Barmi AA, Hosseinifard M (2012) Materials Letters: 28-31.

Boag A, Hughes AE, Wilson, NC, Torpy A, MacRae CM, Glenn AM, Muster TH (2009) Corrosion Science 51: 1565-1568.

Farmer VC (1974) The Infrared Spectra of Minerals. Mineralogical Society London.

Guo Y, Frankel GS (2012) Surface \& Coatings Technology: 3895-3902.

Chen GS, Gao M, and Wei RP (1996) Corrosion 52: $8-15$.

Kendig MW, Buchheit RG (2003) Corrosion 59: 379-400.

Nyquist RA, Kagel RO (1971) Infrared Spectra of Inorganic Compounds. Academic Press New York and London.

Qi J (1), Nemcová A, Walton RJ, Zhou X, Skeldon P, Thompson GE (2016) Thin Solid Films: 270-278.

Qi J (2), Hashimoto T, Walton RJ, Zhou X, Skeldon P, Thompson GE (2016) J. Electrochemical Society: C25-C35. 